\title{
Inflammatory response in ventilated left and collapsed right lungs, serum and pleural fluid, in transthoracic esophagectomy for cancer
}

\author{
Zingg, U ; Forberger, J ; Frey, D M ; Esterman, A J ; Oertli, D ; Beck-Schimmer, B ; Zollinger, A
}

\begin{abstract}
INTRODUCTION: Open, right-sided, transthoracic esophagectomy with one-lung ventilation $(\mathrm{OLV})$ triggers a massive inflammatory reaction. The influence of the OLV on the inflammatory cascade is unclear. Data on the inflammatory response in the ventilated left and collapsed right lung, respectively, are scarce. The aim of this study was to analyze this reaction in bronchoalveolar lavage (BAL) fluid from both lungs, the right pleural space and the peripheral blood, and to study its time course. METHODS: Concentrations of interleukin (IL)-6, IL-8, IL-10 and IL-1RA in the BAL fluids from the right and left lungs, respectively, in the peripheral blood and in the right pleural space in patients undergoing transthoracic esophagectomy for cancer, were determined using enzyme-linked immunosorbent assays in 29 patients. RESULTS: Assay of the pro-inflammatory cytokines in the bilateral BAL fluids showed significantly higher concentrations in the ventilated left lung at the time of extubation. The antiinflammatory response was only seen with respect to IL-1RA, but not IL-10, and was mostly restricted to the ventilated left lung. In the blood, only IL-6, IL-10 and IL-1RA increased, whereas IL-8 showed little change. The response was already observed at the end of surgery, indicating a rapid reaction to the surgical and anesthetic trauma. In the pleural fluid, all cytokine concentrations increased, and the highest values were detected on day one post-surgery, and decreased thereafter. Pulmonary complications or anastomotic leakage were not related to the cytokine concentrations. CONCLUSION: Both the ventilated left and the collapsed right lung showed an inflammatory response. The response was more pronounced on the ventilated left side and the time courses were significantly different. In the blood, the pro-inflammatory IL-6 and both anti-inflammatory cytokines increased early on. All cytokines increased in the pleural cavity. The findings underline the complexity of the inflammatory reaction associated with OLV in transthoracic esophagectomy.
\end{abstract}

DOI: https://doi.org/10.1684/ecn.2009.0180

Posted at the Zurich Open Repository and Archive, University of Zurich

ZORA URL: https://doi.org/10.5167/uzh-36212

Journal Article

Accepted Version

Originally published at:

Zingg, U; Forberger, J; Frey, D M; Esterman, A J; Oertli, D; Beck-Schimmer, B; Zollinger, A (2010). Inflammatory response in ventilated left and collapsed right lungs, serum and pleural fluid, in transthoracic esophagectomy for cancer. European Cytokine Network, 21(1):50-57.

DOI: https://doi.org/10.1684/ecn.2009.0180 


\title{
Inflammatory response in ventilated left and collapsed right lungs, serum and pleural fluid in transthoracic esophagectomy for cancer
}

\section{Differences between the right and left lungs}

\author{
U Zingg ${ }^{1}$, J Forberger ${ }^{2}$, DM Frey ${ }^{1}$, AJ Esterman ${ }^{3}$, D Oertli ${ }^{1}$, B Beck-Schimmer ${ }^{4}$, A \\ Zollinger $^{5}$
}

${ }^{1}$ Department of Surgery, University Hospital Basel, Spitalstrasse, 4031 Basel,

Switzerland

${ }^{2}$ Department of Surgery, Triemli City Hospital Zurich, Birmensdorferstrasse 497, 8063 Zurich, Switzerland

${ }^{3}$ School of Nursing and Midwifery, University of South Australia, Adelaide 5000 SA, Australia

${ }^{4}$ Institute of Anaesthesiology, University Hospital Zurich, Raemistrasse 100, 8091 Zurich, Switzerland

${ }^{5}$ Institute of Anaesthesiology and Intensive Care Medicine, Triemli City Hospital Zurich, Birmensdorferstrasse 497, 8063 Zurich, Switzerland

\author{
Corresponding author \\ Urs Zingg MD \\ Discipline of Surgery \\ University of Adelaide \\ Royal Adelaide Hospital \\ North Terrace \\ Adelaide 5000 SA \\ Australia \\ uzingg@uhbs.ch \\ Ph: +61882224437 \\ Fax: +61 882225896
}

\section{Keywords}

inflammatory response, one-lung ventilation, esophagectomy, broncho-alveolar lavage 


\section{Abstract}

Introduction

Open right-sided transthoracic esophagectomy with one-lung ventilation (OLV) triggers a massive inflammatory reaction. The influence of the OLV on the inflammatory cascade is unclear. Data on the inflammatory response in the ventilated left and collapsed right lung, respectively, is scarce. The aim of this study was to analyze this reaction in bronchoalveolar lavage (BAL) fluid from both lungs, the right pleural space and the peripheral blood.

Methods

Concentrations of interleukin (IL)-6, IL-8, IL-10 and IL-1RA in the BAL fluids from the right and left lungs, respectively, in the peripheral blood and in the right pleural space in patients undergoing transthoracic esophagectomy for cancer was determined with enzyme-linked immune-sorbent assays in 29 patients.

\section{$\underline{\text { Results }}$}

The assay of the pro-inflammatory cytokines of the bilateral BAL fluids showed significant higher concentrations on the ventilated left lung at the time of extubation. The anti-inflammatory response was only seen in IL-1RA, but not in IL-10, and mostly restricted to the ventilated left lung. In the blood, only IL-6, IL-10 and IL-1RA increased whereas IL-8 showed little reaction. The response was observed already at the end of surgery, indicating a fast reaction to the surgical and anesthetic trauma. In the pleural fluid, all cytokine concentrations increased, and the highest values were detected on day one post surgery, and decreased thereafter. Pulmonary complications or anastomotic leakage did not affect the cytokine concentrations.

\section{Conclusion}

Both the ventilated left and the collapsed right lung showed an inflammatory response. The response was more pronounced on the ventilated left side and the time courses were significantly different. In the blood, the pro-inflammatory IL-6 and both antiinflammatory cytokines increased and the response occurred fast. All cytokines

Formatiert: Schriftartfarbe: Automatisch 
increased in the pleural cavity. The findings underline the complexity of the inflammatory reaction associated with OLV in transthoracic esophagectomy. 


\section{Introduction}

Open right-sided transthoracic esophagectomy with one-lung ventilation (OLV) is one of the standard surgical approaches for curative treatment of esophageal cancer (abdomino-thoracic or thoraco-abdomino-cervical esophagectomy). The OLV leads to a complete collapse of the right lung with subsequent shunting of blood and the risk of hypoxemia.

The procedure triggers a massive inflammatory reaction with production of various cytokines such as the pro-inflammatory interleukin-6 (IL-6) and IL-8 and the antiinflammatory cytokines IL-10 and IL-1 receptor antagonist (IL-1RA) [1,2]. Elevated concentrations of these interleukins have been measured in bronchoalveolar lavage (BAL) fluid, peripheral blood, and in the pleural space [3,4]. Elevated levels of antiinflammatory cytokines in bronchoalveolar fluid have been reported to correlate with the development of the acute respiratory distress syndrome (ARDS) and low concentrations of anti-inflammatory cytokines were associated with poor prognosis in patients with ARDS $[5,6]$.

In esophagectomy, pulmonary complications are frequent with rates of up to $40 \%$ [7]. Impaired respiratory mechanics due to thoracotomy and laparotomy, pre-existing pulmonary co-morbidity, and the inflammatory reaction with release of oxygen radicals and resultant lung injury are possible explanations for these complications.

Although a few studies have addressed the production of cytokines and the inflammatory reaction in esophagectomy, the mechanisms are still not well defined. The influence of the OLV on the inflammatory cascade is unclear and the data on the inflammatory reaction in the ventilated left and collapsed right lung, respectively, is scarce. Different mechanisms may induce lung injury after OLV, such as ischemia/reperfusion injury in the collapsed lung, ventilator-induced injury, hyperoxia, 
volume overload and increased capillary stress in the ventilated lung $[8,9,10]$. Cree et al. demonstrated significant higher IL-8 levels in the BAL fluid after surgery compared to the peripheral blood but did not show a difference between the collapsed and ventilated lung groups [4]. However, the BAL fluid samples were taken from different patients. As cytokine production varies substantially between patients, this might have introduced a selection bias.

The aim of this study was to analyze the inflammatory reaction, represented by the concentrations of IL-6, IL-8, IL-10 and IL-1RA in BAL fluid of the ventilated left and collapsed right lungs, in the peripheral blood and in the right pleural space in patients undergoing transthoracic esophagectomy for cancer.

\section{Patients and methods}

From the $1^{\text {st }}$ January 2006 all patients undergoing transthoracic esophagectomy for cancer at the Triemli Hospital Zurich and the University Hospital Basel were assessed for eligibility to be included in a prospective, randomized, double-blinded trial to analyze the influence of n-acetylcysteine (NAC) on pulmonary morbidity (trial ongoing). The trial is registered by the National Library of Medicine at www.clinicaltrials.gov under the number NCT00512265. The study was approved by the Ethics committees of the two participating hospitals. Informed consent was obtained from all patients. In the first 30 patients included in the NAC trial, cytokine analysis was performed for this study. One patient was excluded as an intra-operative decision was made to perform a transhiatal esophagectomy, resulting in data from of 29 patients being available for analysis.

\section{Neoadjuvant treatment, surgery and anesthetic procedure}

All patients with advanced tumors ( $\mathrm{T} 3$ and / or $\mathrm{N}+$ ) received neoadjuvant treatment. This usually entailed chemotherapy with 5-fluorouracil and cisplatin, and an irradiation 
dose of 45-50 Gray. Surgery was performed 6-8 weeks after completion of the combined pre-treatment.

Esophagectomies were done using the abdomino-thoracic (Ivor-Lewis resection) and the thoraco-abdomino-cervical (3-stage) approach in 23 and 6 patients, respectively. In the latter group, the cervical phase was performed simultaneously to the abdominal phase, thus not prolonging the procedure. In all patients the stomach was used as conduit for reconstruction. The anastomosis was either stapled or hand-sewn, according to the surgeon's preference. Two thoracic drains (28 French anterior and 32 French posterior) were inserted into the thoracic cavity before closure of the thoracotomy. The posterior drain was left in place for a minimum of 5 days. A contrast swallow was performed on postoperative day five.

Anesthetic procedures were standardized for all patients including the use of doublelumen endobronchial tubes under fiber-optic control to allow single lung ventilation and use of thoracic epidural catheters with continuous infusion of local anesthetics both intraoperatively (ropivacaine $0.3 \%$ ) and up to five days postoperatively (bupivacaine $0.125 \%$ ). Total intravenous anesthesia was applied using bolus doses of fentanyl and continuous infusions of propofol and remifentanil intraoperatively and tempered until endotracheal extubation. Muscle relaxation (intraoperatively only) was achieved using bolus doses of rocuronium. One-lung ventilation during thoracotomy followed the principles of a lung protective strategy, using pressure-limited or pressure-controlled ventilation modes with tidal volumes of $<7 \mathrm{ml} / \mathrm{kg}$ body weight, positive end-expiratory pressure of $3-5 \mathrm{~cm} \mathrm{H} 2 \mathrm{O}$ and limiting peak inspiratory pressures to $<30 \mathrm{~cm} \mathrm{H} 2 \mathrm{O}$. Inspired oxygen concentration on the ventilated lung was set to $100 \%$ at the beginning and gradually reduced thereafter based on the arterial oxygen tension measured by repeated blood gas analyses $[11,12,13]$. Extubation was performed on the morning of the first postoperative day with the exception of six patients who were extubated within four hours of the completion of the surgery. 
Continuous monitoring included ECG analysis, measurement of arterial oxygen saturation with pulse oxymetry and invasive arterial as well as central venous pressure monitoring. Blood samples were drawn intermittently at predefined time points for blood gas and further laboratory parameter analysis.

\section{BAL, pleural lavage and peripheral blood samples}

Bilateral BAL was performed after intubation, at the completion of surgery and prior to extubation. In the six patients that were extubated within 4 hours postoperatively only the first two bilateral BAL's were performed (at intubation and end of surgery). The bronchoscope was wedged in the lower bronchus of both lungs and a lavage with $50 \mathrm{ml}$ of sterile saline was performed. The BAL fluid was immediately centrifuged at 2000rpm for 15 minutes and the supernatant stored at $-20^{\circ} \mathrm{C}$.

Pleural samples were obtained after amending the initial protocol following the first 12 patients. To analyze the pleural inflammatory reaction, lavage of the pleural space after thoracotomy and before closure of the thoracotomy with $100 \mathrm{ml}$ of sterile saline was performed. On day 1-3, pleural fluid samples were taken in a standardized way directly from the pleural tubes. The fluid was processed as described above for the BAL samples.

Peripheral venous blood samples were obtained at the same time as the BAL and pleural fluid samples on the day of surgery and on day 1-3. Again, the samples were processed as described.

\section{Cytokine assays}

The concentrations of IL-6, IL-8, IL-10 and IL-1RA in the BAL, pleural space and blood samples were determined with enzyme-linked immune-sorbent assays (ELISA, R \& D Systems, Minneapolis, MN, USA). To standardize the BAL fluid samples for optimal comparison, we extrapolated the results retrieved in the ELISA to a sample volume of $10 \mathrm{ml}$. 


\section{$\underline{\text { Statistical analysis }}$}

Comparison of data between the groups was undertaken using Chi-square tests for categorical data, and Wilcoxon signed rank tests for continuous data. To analyze the influence of time on the cytokine response, a regression model using an interaction term for group and time was developed. Postoperative morbidity was classified as surgical, pulmonary or medical. Surgical morbidity included anastomotic leak, thoracic empyema, chyle leak and rethoracotomy or relaparotomy. An anastomotic leak was defined as contrast extravasation during a contrast swallow study. Pulmonary morbidity included postoperative pneumonia, pleural effusion requiring intervention and ARDS. Medical morbidity included cardiac complications such as arrhythmias needing intervention or renal failure.

An analysis to assess whether the concentrations of cytokines in the different compartments were different in patients with and without complications was performed. This analysis was stratified according type of complication: complications that were results of the change of the immune system such as pulmonary and medical complications, pulmonary complications alone and the major surgical complication, anastomotic leakage. Atrial fibrillation was included in the complications that were results of the change of the immune system [14].

Data is presented in mean with standard deviation (SD) or median with inter-quartile range (IQR) as appropriate. Statistical significance for each model was set at $p<0.05$. Statistical analyses were performed with $\mathrm{SPSS} \AA$, Version 16 for Windows and GraphPad InStat Version 3.1a for Macintosh, GraphPad Software, San Diego California USA.

\section{Results}

Patients, pathology and morbidity 
There were 26 men and 3 women in the study group. The mean age was 63.1 years (SD 9.6 years) and mean body mass index was $25.8 \mathrm{~kg} / \mathrm{m} 2$ (SD $4.0 \mathrm{~kg} / \mathrm{m} 2$ ). Preoperative spirometry showed a mean forced expiratory volume (FEV1) of 2.8 liters (SD 0.8 liters) and a mean vital capacity (VC) of 4.1 liters (SD 0.8 liters). The mean percentage FEV1/VC was 69.7\% (SD 11.7\%). Mean cardiac ejection fraction was $58.6 \%$ (SD $8.3 \%$ ). Six patients (20.7\%) had pulmonary comorbidities, five patients (17.2\%) cardiac comorbidities, six patients (20.7\%) presented with non-insulin dependent diabetes and one patient (3.5\%) with pre-existing renal impairment.

There were 19 patients with adenocarcinoma and 10 with squamous cell carcinoma. 17 patients received neoadjuvant radio-chemotherapy and 12 patients proceeded directly to surgery. In 23 patients, an abdomino-thoracic technique and in six patients a thoraco-abdomino-cervical technique was used. No difference in duration of surgery or blood loss occurred between these different techniques (median 270 minutes in both techniques, $p=0.333 ; 500 \mathrm{mls}$ versus $400 \mathrm{mls}, \mathrm{p}=0.609$ ). International Union against cancer (UICC) stages were as follows: four patients (14\%) with stage 0 , seven patients (24\%) with stage I, nine patients (31\%) with stage IIA, six patients (21\%) with stage IIB and three patients (10\%) with stage III.

There was one in-hospital death on postoperative day 30 in a patient with an anastomotic leak and mediastinitis. Morbidity is shown in table 1. The six anastomotic leaks included two cervical and four intra-thoracic. Both cervical leaks were treated conservatively; three patients with intra-thoracic leaks underwent re-thoracotomy and suture repair.

15 patients received NAC and 14 received the placebo (glucose 5\%). No significant differences in cytokine concentration in BAL fluid, peripheral blood and pleural fluid between patients with and patients without NAC were detected. 


\section{BAL fluid cytokine assay}

Both lungs were affected by the surgical procedure. The cytokine response showed substantial variability for the individual patients (Figures 1a-f).The assay of the proinflammatory cytokines of the bilateral BAL fluids showed significant higher concentrations on the ventilated left side at the time of extubation (table 2).

The anti-inflammatory response was only seen in IL-1RA, but not in IL-10, and mostly restricted to the left lung. Again, the response was most marked at time of extubation. The regression model using an interaction term for group and time showed that there was a significant effect in the time progression in IL-6 ( $p=0.003)$, IL-8 ( $p=0.002)$ and IL1RA ( $p=0.001)$, respectively, but not in IL-10 ( $p=0.572)$.

The calculation of the ratios of cytokine increase, taking the cytokine concentration at the intubation as a baseline, showed that the pro-inflammatory cytokines increased substantially, especially IL-6, whereas the anti-inflammatory cytokines reacted less pronounced (Table 2).

\section{Blood cytokine assay}

Of the pro-inflammatory cytokines, only IL-6 increased in the blood whereas IL-8 showed little reaction (table 2). Of the anti-inflammatory cytokines, both IL-10 and IL1RA increased in the blood. The increase was already observed at the end of surgery, thus only a few hours after the surgical trauma occurred. The ratio calculation showed that IL-6 and IL-1RA increased most pronounced (table 3).

\section{Pleural fluid cytokine assay}

All cytokines increased substantially after surgery. The highest concentration was measured in all cytokines on day one post surgery, and decreased thereafter. The ratio calculation showed that all cytokines increased substantially, more than in the BAL fluid or in the blood. IL- 6 and IL-1RA reacted the most with day one ratios of 103 and 25 , respectively. Comparison of cytokine concentrations in the pleural fluid and the 
peripheral blood revealed higher levels in the pleural fluid for all cytokines throughout the measurement period with exception of IL-10 (table 3).

\section{Patients with versus patients without complications}

At no time was any significant difference in interleukin levels of any compartment observed in patients with and without complications that are results of changes in the immune system. Also, no difference between patients with pulmonary complications or anastomotic leak in any of the compartments was detected.

\section{Patients with versus patients without neoadjuvant radiochemotherapy}

A comparison of the initial inflammatory status of the 17 patients who received neoadjuvant radio-chemotherapy compared with the 12 patients that proceeded directly to surgery is shown in Table 4.

\section{Discussion}

In all patients, both lungs were affected There was a difference between proinflammatory cytokine concentrations in BAL fluid of the ventilated left and the Gelöscht: by the OLV and the surgical procedure collapsed right lung. The concentrations of the pro-inflammatory cytokines IL- 6 and IL8 were significantly higher in the ventilated left lung before the delayed extubation. The ratio analysis showed that IL-6 had the most pronounced increase. The antiinflammatory response was represented by IL-1RA, whereas no notable increase in IL10 occurred. There was also a significant influence of time in the concentrations of IL6 , IL-8 and IL-1RA, indicating that not only extend of the inflammatory response is different in the two lungs, but also the timing. To our knowledge, no other study has analyzed cytokine levels and time course during OLV in both lungs in the same patient. Cree at al. examined ventilated left and collapsed right lungs of two different groups of patients and found no significant difference in cytokine concentration [4]. However, as these and other authors state, cytokine concentrations vary considerably 
between patients, thus inflicting a bias [4,5]. Our data support this statement. The different time course of cytokine concentrations may furthermore represent the different mechanisms that trigger the inflammatory reaction. The increase in concentration of the pro-inflammatory cytokines IL-6 and IL-8 is longer and more pronounced in the ventilated left lung compared to the collapsed right lung. A similar finding was described in two groups of patients with a low and high ratio of OLV to total ventilation time $(<35 \%$ and $>35 \%)$, respectively [15]. These authors showed nonsignificant higher BAL fluid IL-6 concentrations in the group with low OLV to total ventilation time ratio. In contrast to our results, these authors did not show any difference in IL-8 concentrations.

A number of factors may be responsible for the development and severity of inflammatory reactions during OLV. The ischemia/reperfusion in the collapsed lung triggers an inflammatory response that may lead to lung injury [9]. In the ventilated lung during OLV, high oxygen concentrations are necessary to maintain adequate oxygenation, producing reactive oxygen species and subsequently triggering an inflammatory reaction [8,16]. Additionally, mechanical ventilation can cause mechanical stress on alveolar walls known as barotrauma or volutrauma, initiating a cytokine response $[17,18,19]$. Our findings indicate that the inflammatory reaction on the ventilated left lung is prolonged compared to the collapsed right lung.

The findings underline the importance of improving the mechanical ventilation in OLV to attenuate the inflammatory reaction and to protect the left lung. Although the principles of a lung protective ventilation strategy were followed in this study (lower tidal volumes, positive end-expiratory pressure and limited peak airway pressures), the inflammatory response to mechanical ventilation appears to be substantial. A number of studies have analyzed the influence of protective ventilation strategies on the cytokine reaction, with inconsistent results [18,20,21,22]. Promising results were obtained in a study comparing two-lung high-frequency jet ventilation with standard 
OLV in patients undergoing transthoracic esophagectomy [23]. The two-lung jet ventilated patients showed a lower PCO2 with adequate oxygenation. However, no measurements to analyze the inflammatory reactions were performed.

In the blood, the pro-inflammatory reaction was mainly represented by the increase of IL-6, but not IL-8, which was detectable only locally in the BAL fluid and the pleural fluid. Both anti-inflammatory cytokines increased in the blood, with IL-1RA being more pronounced. Interestingly, the systemic reaction occurred already at the end of surgery and was therefore very fast since it was observed a few hours after the surgical and anesthetic trauma. Transthoracic esophagectomies have been shown to trigger higher interleukin concentrations in the peripheral blood compared to pancreaticoduodenectomies or transhiatal esophagectomies $[24,25]$. The intrathoracic phase of the operation seems to be responsible for the more severe inflammatory response. In addition, the systemic response may be attenuated by the suppression of circulating white blood cells such as monocytes or T-helper lymphocytes [26]. Whether the production of IL-10 is less attenuated in the peripheral blood, leading to the higher concentrations compared to the BAL fluid, is unclear. Van Sandick et al. showed a depression of IL-10 production in vitro in patients undergoing esophagectomy [26].

The inflammatory response in the compartment where the surgery is performed, i.e. the right sided thoracic cavity, has not been studied previously in detail. Two studies analyzed the concentrations of the pro-inflammatory cytokines IL-6 and IL-8 in pleural drainage fluid and peripheral blood and found significantly higher levels in the pleural samples $[3,27]$. Our results are consistent with these reports. To our knowledge, no study analyzed the course of anti-inflammatory cytokines in the pleural space. Both IL10 and IL-1RA concentrations were markedly higher in the pleural fluid compared to the peripheral blood. The concentrations of the anti-inflammatory cytokines increase until day one after surgery, followed by a subsequent slow decrease. On day three the 
concentrations were still clearly higher than at the beginning of the surgery. This may be influenced by the thoracic drains, which stayed in place for a minimum of five days.

The analysis of the patients with complications versus patients without complications did not reveal any differences at any time point or in any cytokine type. We were not able to reproduce the findings of Szczesny et al, who demonstrated IL-6 and IL-1 in pleural fluid to be a marker for postoperative complications in a small cohort of 27 patients undergoing lobectomy or pneumonectomy [28]. The groups in their study showed significant differences in age (patients with complications were older), and length of surgery (longer in patients with complications). Although the authors argue that these factors are non-immunological, we believe that they still might have had an influence as immune response might be less pronounced in older patients and longer operation times might have had an influence on time course and dimension of immune response.

Pulmonary complications per se did not result in an altered inflammatory response. A subclinical anastomotic leak may also increase the pleural inflammatory response. However, the comparison between the patients who were diagnosed with an anastomotic leak and those without, respectively, did not reveal any differences in cytokine concentrations. As the groups were small, no definite conclusion can be drawn. The clinical relevance of the inflammatory responses in the different compartments is unclear and has yet to be analyzed in further studies.

The patients of this study were also enrolled in a prospective randomized trial analyzing the effect of NAC on pulmonary morbidity. Fifteen patients received NAC and 14 not. This might have influenced the inflammatory response and needs to be acknowledged as a limitation. However, there is no data on the effect of NAC in esophagectomy. We compared the patients with and without NAC and found no 
differences in cytokine response in any compartment. Thus we believe that NAC has not biased the results.

A number of patients underwent neoadjuvant radio-chemotherapy. The interval between pretreatment and surgery was 6-8 weeks. We performed a sub-analysis comparing the initial blood cytokine levels in patients with and without neoadjuvant treatment. The results showed no statistical difference in the cytokines except for IL-6, which is most likely caused by a type 1 error. Literature on the perioperative inflammatory response after neoadjuvant treatment is scarce. Endo et al. assessed cytokine production in patients with small lung cell cancer who underwent preoperative chemotherapy with cisplatin and docetaxel and found an increased cytokine production during the perioperative period [29]. As the numbers in our study are small, careful interpretation of these results is necessary and further studies are necessary to analyze the impact of neoadjuvant treatment on the perioperative cytokine response.

\section{Conclusion}

The findings of this study underline the complexity of the inflammatory reaction associated with transthoracic esophagectomy. The response of pro- and antiinflammatory cytokines arises in both the ventilated left and the collapsed right lungs. The response is more pronounced on the ventilated left side and the time courses are significantly different. In the blood, the pro-inflammatory IL-6 and both antiinflammatory cytokines increased. The response occurred early after the surgical and anesthetic trauma. All cytokines increased in the pleural cavity.

\section{Acknowledgements}

The authors thank Ms. C. Booy and Ms. L. Reyes for skillful laboratory work, Dr. R. Whitfield, MBBS, FRACS, for help in preparation of the manuscript in English and Mr. 
Eric Smith, BSc. for support with the figures and the statistical analysis. The study was supported by departmental grants from the Institute of Anesthesiology, Triemli City Hospital Zurich and Department of Surgery, University Hospital Basel, Switzerland. 


\section{References}

1. Sato N, Koedo K, Kimura Y, Ikeda K, Ogawa M, Saito K, Endo S. Cytokine profile of serum and bronchoalveolar lavage fluids following thoracic esophageal cancer surgery. Eur Surg Res 2001, 33: 279-284

2. Abe T, Oka M, Tangoku A, Hayashi H, Yamamoto K, Yahara N, Morita K, Tabata T, Ohmoto Y. Interleukin-6 production in lung tissue after transthoracic esophagectomy. J Am Coll Surg 2001, 192: 322-329.

3. Morita M, Yoshida R, Ikeda K, Egashira A, Oki E, Sadanaga N, Kakeji Y, Ichiki Y, Sugio K. Acute lung injury following an esophagectomy for esophageal cancer, with special reference to the clinical factors and cytokine levels of peripheral blood and pleural drainage fluid. Dis Esophagus 2008, 21: 30-36.

4. Cree RTJ, Warnell I, Staunton M, Shaw I, Bullock R, Griffin SM, Baudouin SV. Alveolar and plasma concentrations of interleukin-8 and vascular endothelial growth factor following oesophagectomy. Anaesthesia 2004, 59: 867-871.

5. Donnelly SC, Strieter RM, Kunkel SL, Walz A, Robertson CR, Carter DC, Grant IS, Pollok AJ, Haslett C. Interleukin-8 and development of adult respiratory distress syndrome in at-risk patient groups. Lancet 1993, 341: 643-647.

6. Donnelly SC, Strieter RM, Reid PT, Kunkel SL, Burdick MD, Armstrong I, Mackenzie A, Haslett C. The association between mortality rates and decreased concentrations of interleukin-10 and interleukin-1 receptor antagonist in the lung fluids of patients with the adult respiratory distress syndrome. Ann Intern Med $1996,125: 191-196$

7. Avendano CE, Flume PA, Silvestri GA, King LB, Reed CE. Pulmonary complications after esophagectomy. Ann Thorac Surg 2002, 73: 922-926.

8. Baudouin SV. Lung injury after thoracotomy. Br J Anaesth 2003, 91: 132-142.

9. Jordan S, Mitchell JA, Quinlan GJ, Goldstraw P, Evans TW. The pathogenesis of lung injury following pulmonary resection. Eur Respir J 2000, 15: 790-799. 
10. Halbertsma FJ, Vaneker M, Scheffer GJ, van der Hoeven JG. Cytokines and biotrauma in ventilator-induced lung injury: a critical review of the literature. Neth $\mathrm{J}$ Med 2005, 63: 382-392.

11. Karzai W, Schwarzkopf K. Hypoxemia during one-lung ventilation: prediction, prevention, and treatment. Anesthesiology 2009; 110: 1402-1411.

12. De Conno E, Steurer MP, Wittlinger M, Zalunardo MP, Weder W, Schneiter D, Schimmer RC, Klaghofer R, Neff TA, Schmid ER, Spahn DR, Z'graggen BR, Urner M, Beck-Schimmer B. Anesthetic-induced improvement of the inflammatory response to one-lung ventilation. Anesthesiology 2009; 110: 1316-1326.

13. Aschkenasy SV, Hofer CK, Zalunardo MP, Zaugg M, Weder W, Seifert B, Pasch T, Zollinger A. Patterns of changes in arterial PO2 during one-lung ventilation: a comparison between patients with severe pulmonary emphysema and patients with preserved lung function. J Cardiothorac Vasc Anesth 2005; 19: 479-484.

14. Gaudino M, Andreotti F, Zamparelli R, DiCastelnuovo A, Nasso G, Burzotta F, lacoviello L, Donati MB, Schiavello R, Maseri A, Possati G. The -174G/C Interleukin-6 Polymorphism influences postoperative interleukin-6 levels and postoperative atrial fibrillation. Is atrial fibrillation an inflammatory complication? Circulation 2003; 108 (suppl II): 195-199.

15. Ojima H, Kuwano H, Kato H, Miyazaki T, Nakajima M, Sohda M, Tsukada K. Relationship between cytokine response and temporary ventilation during one-lung ventilation in esophagectomy. Hepato-Gastroenterology 2007, 54: 111-115.

16. Li LF, Liao SK, Ko YS, Lee CH, Quinn DA. Hyperoxia increases ventilator-induced lung injury via mitogen-activated protein kinases: a prospective, controlled animal experiment. Crit Care 2007, 11: R25.

17. Dos Santos CC, Slutsky AS. Invited review: mechanisms of ventilator-induced lung injury: a perspective. J Appl Physiol 2000, 89: 1645-55. 
18. Michelet P, D'Journo XB, Roch A, Doddoli C, Marin V, Papazian L, Decamps I, Bregeon F, Thomas P, Auffray JP. Protective ventilation influences systemic inflammation after esophagectomy. Anesthesiology 2006, 105: 911-919.

19. Tandon S, Batchelor A, Bullock R, Gascoigne A, Griffin M, Hayes N, Hing J, Shaw I, Warnell I, Baudouin SV. Peri-operative risk factors for acute lung injury after elective oesophagectomy. $\mathrm{Br} \mathrm{J}$ Anaesth 2001, 86: 633-638.

20. Ranieri VM, Suter PM, Tortorella C, De Tullio R, Dayer JM, Brienza A, Bruno F, Slutsky AS. Effect of mechanical ventilation on inflammatory mediators in patients with acute respiratory distress syndrome: a randomized controlled trial. JMA 1999, 282: 54-61.

21. Wrigge H, Uhlig U, Zinserling J, Behrends-Callsen E, Ottersbach G, Fischer M, Uhlig S, Putensen C. The effects of different ventilatory settings on pulmonary and systemic inflammatory responses during major surgery. Anesth Analg 2004, 98: 775-781.

22. Koner O, Celebi S, Balci H, Cetin G, Karaoglu K, Cakar N. Effects of protective and conventional mechanical ventilation on pulmonary function and systemic cytokine release after cardiopulmonary bypass. Intensive Care Med 2004, 30: 620-626.

23. Buise M, von Bommel J, van Genderen M, Tilanus H, van Zundert A, Gommers D. Two-lung high-frequency jet ventilation as an alternative ventilation technique during transthoracic esophagectomy. J Cardiothorac Vasc Anesth 2009 Feb 24 [Epub ahead of print].

24. Sakamoto K, Arakawa H, Mita S, Ishiko T, Ikei S, Egami H, Hisano S, Ogawa M. Elevation of circulating interleukin 6 after surgery: factors influencing the serum level. Cytokine 1994, 6: 181-186.

25. Mahmoodi M, Mir MR, Daryaei P, Harirchi I, Rezaei N, Mohagheghi MA, MousaviJarrahi A, Nahavandian B, Kavianpour M, Jafari A. Cytokine response following transthoracic and transhiatal esophagectomy in patients with esophageal cancer. Eur Cytokine Netw 2008, 19: 92-98. 
26. van Sandick JW, Gisbertz SS, ten Berge IJ, Moermeester MA, van der Pouw Kraan TC, Out TA, Obertop H, van Lanschot JJ. Immune response and prediction of major infection in patients undergoing transhiatal or transthoracic esophagectomy for cancer. Ann Surg 2003, 237: 35-43.

27. Hisano S, Sakamoto K, Ishiko T, Kamohara H, Ogawa M. IL-6 and soluble receptor levels change differently after surgery both in the blood and the operative field. Cytokine 1997, 9: 447-452.

28. Szczesny TJ, Slotwinski R, Stankiewicz A, Szczygiel B, Zaleska M, Kopacz M. Interleukin 6 and interleukin 1 receptor antagonist as early markers of complications after lung cancer surgery. Eur J Cardiothorac Surg 2007; 31: 719724.

29. Endo S, Sato Y, Hasegawa T, Tetsuka K, Otani S, Saito N, Tezuka Y, Sohara Y. Preoperative chemotherapy increases cytokine production after lung cancer surgery. Eur J Cardiothorac Surg 2004; 26: 787-791. 


\section{Table 1}

Morbidity shown as medical, surgical and pulmonary morbidity.

\begin{tabular}{|c|l|}
\hline $\begin{array}{c}\text { Surgical morbidity total } \\
\text { No } \\
\text { Yes }\end{array}$ & 21 \\
\hline Leak & 8 \\
No & 23 \\
Yes & 6 \\
\hline $\begin{array}{c}\text { Rethoracotomy } \\
\text { No } \\
\text { Yes }\end{array}$ & 25 \\
Relaparotomy & 4 \\
No & \\
Yes & 27 \\
Pulmonary morbidity total & 2 \\
No & 12 \\
Yes & 17 \\
\hline Noffusion & 22 \\
Yes & 7 \\
\hline Pneumonia & \\
No & 16 \\
Yes & 13 \\
\hline No & 28 \\
Yes & 1 \\
\hline NorbS & 22 \\
Yes & 7 \\
\hline Medical morbidity total & \\
\hline
\end{tabular}


Table 2

Comparison of the cytokine levels in the BAL fluid of the right and left lung and the levels in the peripheral blood.

\begin{tabular}{|c|c|c|c|c|c|}
\hline & $\begin{array}{l}\text { BAL COLLAPSED } \\
\text { RIGHT LUNG }\end{array}$ & $\begin{array}{l}\text { RATIO OF } \\
\text { CYTOKINE } \\
\text { RESPONSE } \\
\text { COLLAPSED RIGHT } \\
\text { LUNG* }^{*}\end{array}$ & $\begin{array}{l}\text { BAL VENTILATED } \\
\text { LEFT LUNG }\end{array}$ & $\begin{array}{l}\text { RATIO OF CYTOKINE } \\
\text { RESPONSE } \\
\text { VENTILATED LEFT } \\
\text { LUNG** }\end{array}$ & $\begin{array}{l}\text { P VALUE\# } \\
\text { BAL RIGHT LUNG } \\
\text { COMPARED TO } \\
\text { BAL LEFT LUNG }\end{array}$ \\
\hline $\begin{array}{c}\text { IL-6 (PG/ML), MEDIAN (IQR) } \\
\text { AT INTUBATION } \\
\text { END OF SURGERY } \\
\text { BEFORE EXTUBATION }\end{array}$ & $\begin{array}{l}54(17-113) \\
959(135-2297) \\
428(174-1217)\end{array}$ & $\begin{array}{l}12.1 \\
6.4\end{array}$ & $\begin{array}{l}48(29-114) \\
669(328-1391) \\
1045(137-5829)\end{array}$ & $\begin{array}{l}9.4 \\
12.8\end{array}$ & $\begin{array}{l}0.598 \\
0.258 \\
0.044\end{array}$ \\
\hline $\begin{array}{c}\text { IL-8 (PG/ML), MEDIAN (IQR) } \\
\text { AT INTUBATION } \\
\text { END OF SURGERY } \\
\text { BEFORE EXTUBATION }\end{array}$ & $\begin{array}{l}2015(498-3681) \\
4933(1738-21384) \\
11515(4397-18807)\end{array}$ & $\begin{array}{l}3.9 \\
4.1\end{array}$ & $\begin{array}{l}2077(1152-4398) \\
5472(1540-11437) \\
23097(7696-62921)\end{array}$ & $\begin{array}{l}2.3 \\
6.6\end{array}$ & $\begin{array}{l}0.745 \\
0.150 \\
0.038\end{array}$ \\
\hline $\begin{array}{c}\text { IL-10 (PG/ML), MEDIAN (IQR) } \\
\text { AT INTUBATION } \\
\text { END OF SURGERY } \\
\text { BEFORE EXTUBATION }\end{array}$ & $\begin{array}{l}0(0-7) \\
35(0-79) \\
0(0-9)\end{array}$ & $\begin{array}{l}2.5 \\
0\end{array}$ & $\begin{array}{l}0(0-8) \\
15(0-33) \\
3(0-25)\end{array}$ & $\begin{array}{l}2.1 \\
1.3\end{array}$ & $\begin{array}{l}0.715 \\
0.063 \\
0.117\end{array}$ \\
\hline $\begin{array}{c}\text { IL-1RA (PG/ML), MEDIAN (IQR) } \\
\text { AT INTUBATION } \\
\text { END OF SURGERY } \\
\text { BEFORE EXTUBATION }\end{array}$ & $\begin{array}{l}5838(2035-12379) \\
11390(5659-40199) \\
10245(6689-18663)\end{array}$ & $\begin{array}{l}2.4 \\
2.6\end{array}$ & $\begin{array}{l}6519(2600-12402) \\
8775(3029-23165) \\
33780(9041-109282)\end{array}$ & $\begin{array}{l}1.1 \\
3.2\end{array}$ & $\begin{array}{l}0.745 \\
0.089 \\
0.092\end{array}$ \\
\hline
\end{tabular}

${ }^{*}$ Concentration at intubation as base line for calculation of ratio

\# Wilcoxon paired samples test 
Table 3

Comparison of the cytokine levels in the pleura fluid with the levels in the peripheral blood. The pleural samples were taken immediately after the thoracotomy and before closure of the thoracotomy. On day 1-3 the pleural and peripheral blood samples were taken at the same time.

\begin{tabular}{|c|c|c|c|c|c|}
\hline & PLEURAL FLUID & $\begin{array}{l}\text { RATIO OF CYTOKINE } \\
\text { RESPONSE PLEURAL } \\
\text { FLUID* }\end{array}$ & $\begin{array}{l}\text { PERIPHERAL } \\
\text { BLOOD }\end{array}$ & $\begin{array}{l}\text { RATIO OF CYTOKINE } \\
\text { RESPONSE } \\
\text { PERIPHERAL } \\
\text { BLOOD* }\end{array}$ & $\begin{array}{l}\text { P VALUE\# } \\
\text { PLEURAL FLUID } \\
\text { VERSUS BLOOD }\end{array}$ \\
\hline $\begin{array}{l}\text { IL-6 (PG/ML), MEDIAN (IQR) } \\
\text { AT THORACOTOMY/INTUBATION } \\
\text { END OF SURGERY } \\
\text { DAY } 1 \\
\text { DAY } 2 \\
\text { DAY } 3\end{array}$ & $\begin{array}{l}399(0-702) \\
1799(659-3046) \\
52124(27311-68355) \\
26755(16796-41109) \\
10583(7047-28171)\end{array}$ & $\begin{array}{l}2.5 \\
103.3 \\
39.1 \\
19.5\end{array}$ & $\begin{array}{l}0(0-12) \\
134(76-208) \\
146(98-224) \\
86(56-145) \\
51(24-98)\end{array}$ & $\begin{array}{l}11.1 \\
11.9 \\
4.9 \\
4.2\end{array}$ & $\begin{array}{l}<0.001 \\
<0.001 \\
<0.001 \\
<0.001 \\
<0.001\end{array}$ \\
\hline $\begin{array}{l}\text { IL-8 (PG/ML), MEDIAN (IQR) } \\
\text { AT THORACOTOMY/INTUBATION } \\
\text { END OF SURGERY } \\
\text { DAY } 1 \\
\text { DAY } 2 \\
\text { DAY } 3\end{array}$ & $\begin{array}{l}28(0-216) \\
222(31-319) \\
705(296-1232) \\
589(230-1289) \\
417(201-951)\end{array}$ & $\begin{array}{l}1.1 \\
6.6 \\
5.3 \\
2.9\end{array}$ & $\begin{array}{l}0(0-22) \\
10(0-48) \\
0(0-45) \\
0(0-28) \\
0(0-38)\end{array}$ & $\begin{array}{l}1.1 \\
1.4 \\
1.3 \\
1.2\end{array}$ & $\begin{array}{l}0.040 \\
<0.001 \\
<0.001 \\
<0.001 \\
<0.001\end{array}$ \\
\hline $\begin{array}{l}\text { IL-10 (PG/ML), MEDIAN (IQR) } \\
\text { AT THORACOTOMY/INTUBATION } \\
\text { END OF SURGERY } \\
\text { DAY } 1 \\
\text { DAY } 2 \\
\text { DAY } 3\end{array}$ & $\begin{array}{l}0(0-25) \\
10(0-44) \\
317(237-392) \\
234(152-285) \\
155(106-217)\end{array}$ & $\begin{array}{l}0.8 \\
11.9 \\
9.4 \\
7.3\end{array}$ & $\begin{array}{l}15(0-258) \\
75(38-276) \\
62(12-323) \\
46(6-281) \\
57(6-317)\end{array}$ & $\begin{array}{l}1.2 \\
1.3 \\
1.4 \\
1.4\end{array}$ & $\begin{array}{l}0.022 \\
<0.001 \\
0.051 \\
0.098 \\
0.855\end{array}$ \\
\hline $\begin{array}{l}\text { IL-1RA (PG/ML), MEDIAN (IQR) } \\
\text { AT THORACOTOMY/INTUBATION } \\
\text { END OF SURGERY } \\
\text { DAY } 1 \\
\text { DAY } 2 \\
\text { DAY } 3\end{array}$ & $\begin{array}{l}62(0-803) \\
1137(319-1837) \\
7152(3834) \\
5314(11758) \\
3807(3457-8991)\end{array}$ & $\begin{array}{l}3.0 \\
24.9 \\
5.9 \\
4.3\end{array}$ & $\begin{array}{l}63(0-780) \\
5053(1048-11533) \\
961(357-1502) \\
436(171-1297) \\
397(145-2085)\end{array}$ & $\begin{array}{l}9.8 \\
1.6 \\
1.1 \\
1.7\end{array}$ & $\begin{array}{l}0.380 \\
<0.001 \\
<0.001 \\
<0.001 \\
<0.001\end{array}$ \\
\hline
\end{tabular}

${ }^{*}$ Concentration at intubation as base line for calculation of ratio

\# Wilcoxon paired samples test 
Table 4

Comparison of basic serum cytokine levels of patients who underwent neoadjuvant radio-chemotherapy and patients who proceeded directly to surgery.

\begin{tabular}{|l|l|l|l|}
\hline & $\begin{array}{l}\text { NEOADJUVANT } \\
\text { TREATMENT } \\
\mathrm{N}=17\end{array}$ & $\begin{array}{l}\text { NO NEOADJUVANT } \\
\text { TREATMENT } \\
\mathrm{N}=12\end{array}$ & P VALUE\# \\
\hline IL-6 (PG/ML), MEDIAN (IQR) & $3(0-18)$ & $0(0-0)$ & \\
\hline IL-8 (PG/ML), MEDIAN (IQR) & $0(0-50)$ & $0(0-0)$ & 0.040 \\
\hline IL-10 (PG/ML), MEDIAN (IQR) & $50(0-694)$ & $12(0-32)$ & 0.088 \\
\hline IL-1RA (PG/ML), MEDIAN (IQR) & $139(0-1586)$ & $43(0-263)$ & 0.262 \\
\hline
\end{tabular}

\#Mann-Whitney-U test 


\section{Figure 1a}

Course of the IL- 6 concentrations on the right side in the 29 individual patients at intubation, at the end of surgery and before extubation.

\section{Figure 1b}

Course of the IL-6 concentrations on the left side in the 29 individual patients at intubation, at the end of surgery and before extubation.

\section{Figure 1c}

Course of the IL-8 concentrations on the right side in the 29 individual patients at intubation, at the end of surgery and before extubation.

\section{Figure 1d}

Course of the IL-8 concentrations on the left side in the 29 individual patients at intubation, at the end of surgery and before extubation.

\section{Figure 1e}

Course of the IL-1RA concentrations on the right side in the 29 individual patients at intubation, at the end of surgery and before extubation.

\section{Figure 1f}

Course of the IL-1RA concentrations on the left side in the 29 individual patients at intubation, at the end of surgery and before extubation. 